\title{
Re-designing Fashion Design Curricula for a New Generation of Learners
}

Brooke Brandewie, Assistant Professor, University of Cincinnati

Injoo Kim, Professor, University of Cincinnati

\section{Introduction}

The world is shifting dramatically as accelerating technology, enhanced smart devices, and artificial intelligence influence lifestyle and society, as characterized by Klaus Schwab's Fourth Industrial Revolution (4IR). The exact impacts of such 4IR technologies on society and the planet are still unknown - but the fact that they will bring profound and rapid change seems all but certain (Penprase, 2018). As Gen $\mathrm{Z}$ and Millennials are transitioning into higher education and the workforce, a gap between what teachers are teaching today and the unknown needed skills of the future is widening (Weidmer, 2015). As leaders in higher education, it is our responsibility to consider these critical factors as we shape curriculum development for the short and long term, since designing future-ready curricula is a key action to transform education ecosystems (Zahidi, 2017).

The fashion industry is experiencing a revolution not only by rapidly evolving technology, but from consumer demands for more sustainable and responsible practices. Fashion institutes, academies and universities all over the world keep training their students to become catwalk designers, highly individual stars and divas, to be discovered by luxury brands, yet the consumers of today and tomorrow are going to choose for themselves, creating and designing their own wardrobes (Edelkoort, 2015). As fashion design is inherently hands-on and practice-driven, how do we balance traditional making skills while integrating rapidly expanding technologies? What is considered fundamental fashion design knowledge? Are we ready to instruct this new generation of learners with consideration to their motivations, attitudes and values, while also enhancing our own technological competencies in the process?

\section{Objectives / Aim}

The purpose of this paper is to share the pedagogical research approach that faculty employed between 2015-2017 to assess the Fashion Design Program at the University of Cincinnati, identify problems, forecast curricular directions, and begin to translate these findings into actionable outcomes. The paper describes activities and key outcomes with the aim to contribute to the broader conversation around holistic pedagogical strategies for fashion design curriculum development.

\section{Activities}

Since the 2015 academic year, a curriculum visioning task force of senior and junior faculty was formed. We reviewed the context of the existing curriculum to re-position the program. The faculty met bi-weekly for four semesters to conduct the following key activities. 1) The first phase focused on conducting a program assessment. This included evaluating the program's existing resources to understand issues, and

Published under a Creative Commons Attribution License (https://creativecommons.org/licenses/by/4.0/), which permits unrestricted use, distribution, and reproduction in any medium, provided the original work is properly cited.

ITAA Proceedings, \#76 - https: / /itaaonline.org 
surveying students and faculty members to gauge current needs and success criteria regarding user experience and space utilization. 2) We identified our program's current strengths and weaknesses. 3) Faculty also conducted extensive benchmarking, examining 20 international and national fashion design departments/schools, in order to assess indicators of quality as well as positioning. 4) We surveyed postgraduates and industry members to better understand what industry is looking for and what we can provide.

\section{Outcomes}

Through these varied approaches in collecting data, faculty synthesized the findings to establish four core foundational pillars for the future direction of the program, which are sustainability, design research (interdisciplinary), technology, and practice.

Faculty identified success factors and issues with space utilization and resources (tools/equipment). Key factors for success ranged from both functional and psychological requirements, including ample table space, individual locked storage, available dress forms, etc., along with consideration to social/privacy balance, creating a comfortable environment, and encouraging materials and methods for exploration. From benchmarking academic institutions, we identified that key strengths are our close relationship with industry and our positioning to carry out interdisciplinary design research. Building upon these insights, our survey analysis from 65 post-graduate participants indicated that the most important skills fashion design students should know (in order of importance) includes Technology / Software skills, Critical Thinking / Problem solving, Materials/ Textiles skills, followed by Interdisciplinary design. When asked what should be emphasized in curriculum development (open-ended responses), over half suggested technical and software skills.

In conclusion, because of this assessment and review, the task force's greatest achievement was that these efforts enabled the Fashion Design Program to secure funding to establish two labs: a Sewing Technology Lab and a Textiles Innovation Lab. Also, extensive effort was made amongst the faculty to procure stateof-the-art equipment that best aligns with industry standards while remaining accessible for students. These labs will enable us to carry out our four pillars that we identified as important directions (sustainability, design research, technology and practice), while promoting interdisciplinary teaching and research amongst faculty members. Given this preliminary ground work, we are now able to move into course content development in order to accommodate these shifting requirements.

Published under a Creative Commons Attribution License (https://creativecommons.org/licenses/by/4.0/), which permits unrestricted use, distribution, and reproduction in any medium, provided the original work is properly cited.

ITAA Proceedings, \#76 - https://itaaonline.org 


\section{References:}

Edelkoort, L. (2015). ANTI_FASHION, a manifesto for the next decade. Trend Union. pp 1-7.

Penprase B.E. (2018). The Fourth Industrial Revolution and Higher Education. In: Gleason N. (Eds.), Higher Education in the Era of the Fourth Industrial Revolution (pp. 207-229). Singapore: Palgrave Macmillan.

Schwab, K. (2017). The Fourth Industrial Revolution. New York: Crown Business.

Wiedmer, T. (2015). Generations do differ: Best practices in leading traditionalists, boomers, and generations X, Y, and Z. Delta Kappa Gamma Bulletin, 82(1), 51-58. Retrieved from https://search.proquest.com/docview/1770514324?accountid=2909

Zahidi, S. (2017, January 4). We may have less than 5 years to change how we learn, earn and care. https://www.weforum.org/agenda/2017/01/realizing-human-potential-skills-jobs-care-work/

Page 3 of 3

(c) 2019 The author(s). Published under a Creative Commons Attribution License (https://creativecommons.org/licenses/by/4.0/), which permits unrestricted use, distribution, and reproduction in any medium, provided the original work is properly cited.

ITAA Proceedings, \#76 - https: //itaaonline.org 